\title{
The Level of Awareness on Thyroid Disorders
}

\section{${ }^{1}$ Sibel Ocak Serin, ${ }^{2}$ Muzaffer İlhan, ${ }^{3}$ Seda Ahcı, ${ }^{4}$ Yıldız Okuturlar, ${ }^{1}$ Güven Koc, ${ }^{1}$ Tulay Eyupgiller, ${ }^{1}$ Rıdvan Sivritepe, ${ }^{1}$ Sema Ucak Basat \\ ${ }^{1}$ Department of Internal Medicine, Umraniye Education and Research Hospital, Istanbul, Turkey 2Division of Nephrology, Umraniye Education and Research Hospital, Istanbul, Turkey \\ ${ }^{3}$ Department of Family Medicine, Umraniye Education and Research Hospital, Istanbul, Turkey \\ ${ }^{4}$ Department of Internal Medicine, Bakirkoy Dr. Sadi Konuk Education and Research Hospital, Istanbul, Turkey}

\section{Objectives:}

To evaluate the level of awareness among patients with thyroid disorders presenting to our hospital and determine patient profiles.

\section{Methods:}

\section{Results:}

\section{Conclusions:}

An interview was conducted with a total of 107 patients (4 males [3.7\%] and 103 females [96.3\%]) with a mean age of 46 years. Of these patients, 85 (79.4\%) attended follow-up visits for more than a one-year period and most patients $(n=56)$ were seen at least three times in the last one year $(52.4 \%)$. Of these patients, $69(64.5 \%)$ had hypothyroidism, $11(10.3 \%)$ had hyperthyroidism, and the remaining 27 patients $(25.2 \%)$ had euthyroid nodular goitre. It was found that 78 patients $(72.9 \%)$ were inaccurately or incompletely informed about their disease. Of the patients, $54(50.4 \%)$ were aware that they needed to use iodized salt and 41 patients (38.4\%) were not aware of how to use the salt. When the patients in the study were asked whether they were aware of food and drugs interacting with levothyroxine, 55 patients (86\%) were not aware of these food and drugs. Approximately $30 \%$ of patients used iron supplements and proton pump inhibitors together with levothyroxine.

The present study was conducted using a survey technique on patients aged between 18 and 75 years, who were admitted to our hospital for follow-up between December 1, 2014 and December 31, 2014. The pregnant women and those with a thyroid malignancy and patients who did not consent for the study were excluded. Demographic data such as age, gender, educational level, disease duration, control frequency as well as drug usage pattern, dose, duration and whether or not the patient received fixed dose drug regimen and food/drugs that are not to be taken with the drug were recorded. Type of salt used by the patients was also recorded.

The patients with thyroid disorders had a low level of awareness and low level of knowledge about their disease, follow-up data and their treatments. The physicians must make an endeavor to increase the level of awareness among the patients.

\section{References:}

1.Tan GH, Gharib H. Thyroid incidentalomas: management approaches to nonpalpable nodules discovered incidentally on thyroid imaging. Annals of internal medicine 1997;126(3): 226-31.

2.Urgancıoğlu İ HH. Türkiye'de endemik guatr. Cerrahpaşa Tıp Merkezi 1988

3.Zimmermann MB, Jooste PL, Pandav CS. Iodine-deficiency disorders. Lancet 2008; 372(9645):1251-62.

4.Anaforoglu I, Algun E, Incecayir O, Topbas M, Erdogan MF. Iodine status among pregnant women after mandatory salt iodisation. The British journal of nutrition 2016;115(3): 405-10.

5.Erdogan MF, Agbaht K, Altunsu T, Ozbas S, Yucesan F, Tezel B et al. Current iodine status in Turkey. Journal of endocrinological investigation 2009;32(7):617-22. 